\title{
Traffic planning for non-homogeneous traffic
}

\author{
GEETAM TIWARI $^{1}$, JOSEPH FAZIO ${ }^{2}$ and SUSHANT GAURAV ${ }^{1}$ \\ ${ }^{1}$ Transportation Research and Injury Prevention Programme, Indian Institute of \\ Technology, Hauz Khas, New Delhi 110016 \\ ${ }^{2}$ Civil and Architectural Engineering Department, Illinois Institute of \\ Technology, Illinois, Chicago, USA \\ e-mail: geetamt@gmail.com
}

\begin{abstract}
Traffic on Indian roads (both urban and inter-urban) consists of a variety of vehicles. These vehicles have widely different static and dynamic characteristics. The traffic is also very different from homogeneous traffic which primarily consists of motorized vehicles. Homogeneous traffic follows strict lane discipline as compared to non-homogeneous traffic. Western traffic planning methodologies mostly address the concerns of homogeneous traffic and therefore often prove inadequate in solving problems involving non-homogeneous traffic conditions as found in Indian cities. This paper presents studies conducted on non-homogeneous traffic. Section 1 presents a methodology to verify the continuity equation, the basic block of any traffic planning analysis. In $\S 2$, the methodology developed is applied to modify the Highway Capacity Manual (HCM) 2000 density method to derive passengercar equivalencies (PCEs) or units (PCUs) for heavy vehicles and recreational vehicles. These PCUs appear as 'ET' and 'ER' in HCM tables. The density method assumes motorized, four-wheeler traffic, i.e., homogeneous traffic, and does not include motorized three-wheelers, motorized two-wheelers, and non-motorized traffic often present on Indian highways. By modifying the density method to represent non-homogeneous traffic, which includes significant percentages of motorized, three-wheelers, motorized two-wheelers, and non-motorized traffic entities, one can derive more accurate passenger car units for Indian conditions. Transport professionals can use these PCU values for accurate capacity, safety, and operational analysis of highways carrying non-homogeneous traffic.
\end{abstract}

Keywords. Non-homogeneous traffic; non-motorized traffic; passenger-car units; modified density method; traffic simulation.

\section{Introduction}

\subsection{Homogeneous and non-homogeneous traffic}

The best way to illustrate the difference between homogeneous and non-homogeneous traffic at non-intersection segments is to compare the photographs in figures 1 and 2. Homogeneous traffic has strict lane discipline and has traffic entity types whose physical dimensions do not vary much. The Highway Capacity Manual 2000 (HCM) of USA mentions six traffic 


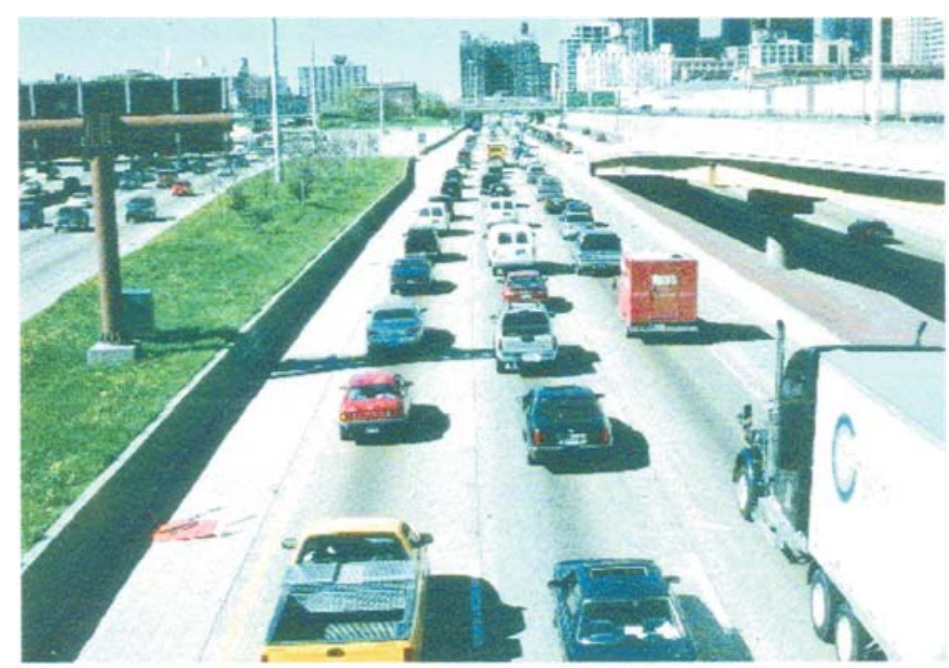

Figure 1. Homogeneous traffic.

entity types: (a) passenger car including vans, (b) heavy vehicle including buses and trucks, (c) recreational vehicle, (d) motorcycle, (e) pedestrian, and (f) bicycle (HCM 2000). HCM mentions motorcycles, but indicates that motorcycles are a small percentage of registered vehicles in USA. Motorcycles are not included in any HCM methodologies.

Some may describe non-homogeneous traffic as chaotic where loose-lane discipline prevails (figure 2). In addition to passenger cars, motorized two-wheelers, motorized three-wheelers, mini-trucks, mini-buses, bicycles, pedestrians, animals, animal-drawn carts, and vendor pushpull carts are usually present on the road. The physical dimensions of the traffic entities greatly vary. Operationally, acceleration and deceleration characteristics also vary because non-motorized traffic entities exist along with motorized vehicles on the road. A facility with non-homogeneous traffic has been defined when its peak hour volume has less than $85 \%$ passenger cars and less than 90\% passenger cars and heavy vehicles (Fazio \& Tiwari 1995).

Most transportation engineering work depends on the use of continuity equations and passenger car units derive from relatively homogenous traffic. In this paper, we present our work on: (i) the development of continuity equations for non-homogenous traffics and (ii) derivations of passenger car units for non-homogenous traffic using the modified density method.

\section{Continuity equations}

\subsection{Homogeneous traffic}

The continuity equation of traffic flow for homogeneous traffic is (Gerlough \& Huber 1975)

$$
k=q / \bar{u}_{s},
$$

where $q$ is traffic flow across a lane or lanes in vehicles per hour, $\bar{u}_{s}$ the space mean speed in kilometers per hour (miles per hour), and $k$ the traffic density in a lane or lanes in vehicles per kilometer (vehicles per mile). Equation (1) assumes constant spacing and constant speed, i.e., an uncongested condition with moderate to slightly high volume. Another name for 


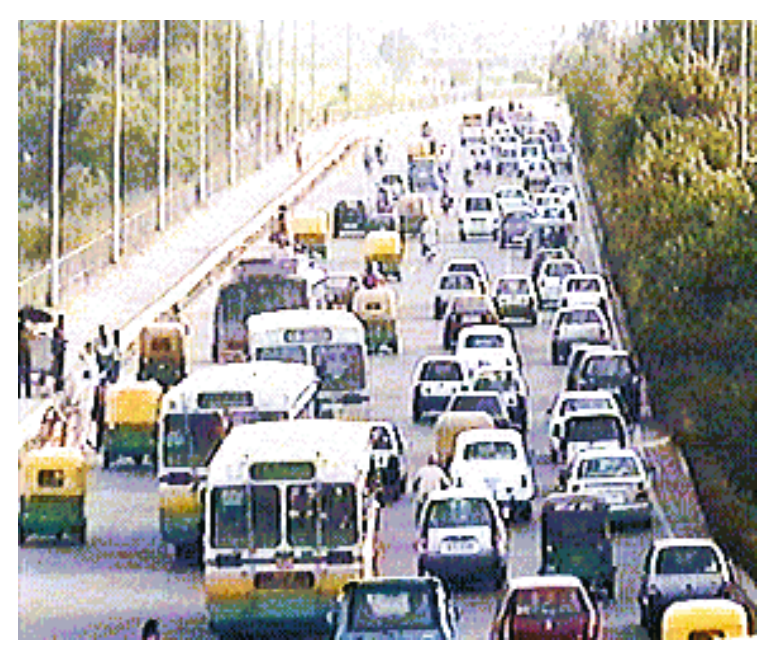

Figure 2. Non-homogeneous traffic.

this equation is the fundamental identity or fundamental equation of traffic flow. Wardrop originally developed the equation (Wardrop 1952). Gerlough and Huber justify the equation on the 'analysis of units' (Gerlough \& Huber 1975). Another assumption that Wardrop makes and which many ignore is that the equation applies only to homogeneous traffic, i.e. 'It follows that the density of this stream in space, that is to say, the number of vehicles per unit length [emphasis added] of road at any instant (the concentration), is given by $k_{i}=q_{i} / v_{i} i=$ $1,2, \ldots, c \ldots$ ' (Wardrop 1952).

For homogeneous traffic, concentration uses unit length per lane because traffic streams usually flow in orderly columns. Concentration across the entire highway width in one traffic direction becomes a matter of adding the individual concentrations in each lane that comprises the total highway width.

\subsection{Non-homogeneous traffic}

Because Wardrop developed the original continuity equation from homogeneous traffic characteristics, an adjustment must occur to reflect non-homogeneous traffic characteristics yet still maintain the basic relationship in the original equation. Many entity types comprise non-homogeneous traffic. Each type has an average concentration in the highway area. The validation of the (2) uses nonhomogeneous traffic field data:

$$
\bar{k}_{j}=\left(q_{j} / W\right) / \bar{u}_{s, j},
$$

where $j$ is the traffic entity type, $\bar{k}_{j}$ the average number of traffic entities of type $j$ per unit area of highway, $W$ the cross-sectional width for measuring flow, $q_{j}$ the number of traffic entities of type $j$ crossing the cross-sectional line of width $W$ during a time interval, and $\bar{u}_{s, j}$ the space mean speed of traffic entities of type $j$ that completely traverse the length of the highway area. An assumption is that $W$ is constant throughout the highway segment for all traffic entity types.

This modified continuity equation also passes the 'analysis of units'. Equation (2) is subject to the same assumption of constant spacing and speed as in the original Wardrop equation. 
Non-homogeneous traffic data collection for validation must occur under uncongested conditions with moderate to slightly high volumes. Since all traffic entity types share the same highway area at any time instant, the Equation (3) holds:

$$
\bar{k}_{n t}=\sum_{j=1}^{N} \bar{k}_{j},
$$

where $k_{n t}$ is the average number of non-homogeneous traffic entities per unit area of highway, and $N$ the total number of entity types in the non-homogeneous traffic stream. In this case, $N$ equals five as explained below. Further, the sum of the traffic subflows of the individual traffic entity types comprising non-homogeneous traffic is the total non-homogeneous traffic flow:

$$
\frac{q_{n t}}{W}=\sum_{j=1}^{N} \frac{q_{j}}{W},
$$

where $q_{n t}$ is total non-homogeneous traffic flow.

Vehicles based on similar traffic operating characteristics are grouped into five types: (a) motorized four-wheelers (M4W) viz. cars, vans, minivans, jeeps, and light pick-up trucks; (b) heavy vehicles (HV) viz. trucks, mini-trucks, buses; and mini-buses; (c) motorized threewheelers (M3W) such as autorickshaws, high capacity autorickshaws, and tempos; (d) motorized two-wheelers (M2W) such as motorcycles, motor scooters, and mopeds; and (e) nonmotorized vehicles (NMV) which include bicycles and cycle-rickshaws. Since the number of pedestrians, animals, pushcarts, pull carts, and animal-drawn carts, i.e., non-motorized traffic entities (NME), on the highways is insignificant, these were not included in this experiment.

\subsection{Methodology}

2.3a Data collection and processing: Data was collected in Delhi using three mid-block sites using camcorder and video technologies and procedures described by Fazio \& Tiwari (1995). Data reduction was done in the laboratory under controlled conditions. A strategically positioned, stationary camcorder captured a $40 \mathrm{~m}(130 \mathrm{ft})$ to $60 \mathrm{~m}(200 \mathrm{ft}) \mathrm{long}$, highway section. This facilitated viewing of the entire highway width in one direction. The calibration of distances to the video monitor involved using a measuring wheel to mark length and width distances at the site. In the laboratory, the observers knew these distances by watching the video monitor and the marked distances. Videotaping at the three sites occurred during a peak period. The highest, consecutive, twelve, 5-minute counts constituted the peak hour at each site. During the peak hour in which the camcorder operated, observers reported no traffic congestion at the three sites. In addition, the three mid-block sites had no bus stops that would influence non-homogeneous traffic flow.

In the laboratory, observers first watched the time-stamped videotape to count traffic entities that traversed a cross-sectional line whose length was the site's unidirectional highway width. Observers tallied their counts by traffic entity type every 5-minutes during this period. At all three sites in the peak hour, passenger cars comprised less than $85 \%$ of the traffic, and cars and trucks comprised less than $90 \%$; non-homogeneous traffic prevailed at all three sites.

Secondly, the observers reviewed the videotape to sample traffic entity speeds through the section's length. Observers noted the travel time in which every fifth traffic entity traversed between $40 \mathrm{~m}$ and $60 \mathrm{~m}$. From the noted time and distance that the entity traverses, the derivation of speed of the sampled entity occurred. Taking the mean of traffic entity speeds produced the time mean speed for that traffic entity type. 
After adjustment for non-homogeneous traffic, the equation for space mean speed becomes:

$$
\bar{u}_{s, j}=n_{j} L / \sum_{i=1}^{n_{j}} t_{i, j},
$$

where $i$ is the $i$ th traffic, $j$ the traffic entity type, $\bar{u}_{s, j}$ the space mean speed of traffic entity type $j$, and $n_{j}$ the number of traffic entities in type $j, t_{i j}$ is the time it takes the $i$ th traffic entity of type $j$ to travel across the length of the highway area, and $L$ is the longitudinal length of section of the highway area. Equation (5) is used in deriving space mean speeds of each non-homogeneous traffic entity type. An equivalent equation to calculate space mean speeds of non-homogeneous traffic types is the harmonic mean equation:

$$
\bar{u}_{s, j}=\frac{1}{\frac{1}{n_{j}} \sum_{i=1}^{n_{j}} \frac{1}{u_{i, j}}},
$$

where, $u_{i, j}$ is the speed of the $i$ th traffic entity in type $j$ to travel across an area of highway. An approximation for space mean speed from time mean speed for a particular time interval is:

$$
\bar{u}_{s, j}=\bar{u}_{t, j}-\frac{\sigma_{t, j}^{2}}{\bar{u}_{t, j}}
$$

where $\bar{u}_{s, j}$ is the arithmetic mean speed of traffic entities comprising type $j$, and $\sigma_{t, j}^{2}$ the speed variance of traffic entities in type $j$.

The observers rewound the videotape to sample traffic-entity type densities on the highway area. Every 30 seconds, observers freeze-framed the videotape and counted the traffic entities by type on the roadway area. The 30-second, sampling rate allowed different entities to occupy the highway area, i.e., the snap-shots were independent of one another. From these sampled, instantaneous densities, one derived the average density by type during the same 5-minute intervals where volume and speed observations occurred.

2.3b Relationship of space mean speed between non-homogeneous traffic and individual traffic entity types: The space mean speed of non-homogeneous traffic is not simply the weighted space mean speed of the individual non-homogeneous traffic entity types by flow. Substituting for $\bar{k}_{n t}$ in (3) produces:

$$
\frac{q_{n t} / W}{\bar{u}_{s, n t}}=\sum_{j=1}^{N} \bar{k}_{j}
$$

Solving for $\bar{u}_{s, m}$ :

$$
\bar{u}_{s, n t}=\frac{q_{n t} / W}{\sum_{j=1}^{N} \bar{k}_{j}} .
$$

Substituting $\bar{k}_{j}$ with (2):

$$
\bar{u}_{s, n t}=\frac{q_{n t} / W}{\sum_{j=1}^{N} \frac{q_{j} / W}{\bar{u}_{s, j}}}=\frac{q_{n t}}{\sum \frac{q_{j}}{\bar{u}_{s, j}}} .
$$


Expressing non-homogeneous traffic as a percent composition of total flow:

$$
\bar{u}_{s, n t}=\frac{100}{\sum_{j=1}^{N} \frac{\%_{j}}{\bar{u}_{s, j}}},
$$

where $\%_{j}$ is the traffic composition percent of traffic entity type $j$. Thus, the space mean speed of non-homogeneous traffic is the weighted, harmonic space mean speed of the individual non-homogeneous traffic entity type by flow.

2.3c Data summary The summarization of the density data based on videotape observations is in table 1 which shows average, 30-second, sampled densities. Using the nonhomogeneous traffic continuity equation of (2), the resultant traffic concentrations appear in table 2. Comparing the traffic concentrations in table 1 to those in table 2 produced measures of association by traffic entity type and by site.

\subsection{Experimental results}

The association between observed and derived densities given 36 observations for each traffic entity type had correlation coefficients with zero intercept of +0.89 for non-heavy four-wheel vehicles, +0.85 for heavy vehicles, +0.90 for motorized three-wheel vehicles, +0.83 for motorized two-wheel vehicles and +0.50 for non-motorized vehicles. Given all 180 observations, the correlation coefficient with no intercept is +0.78 when combining all traffic vehicle types. Given the variability that exists in a traffic stream due to driver behaviour, a correlation coefficient of +0.70 or more represents a strong correlation. Considering the correlation coefficients by site, 60 observations for each site revealed that the density association with no intercept for the three sites were $+0 \cdot 84,+0 \cdot 73$, and $+0 \cdot 77$.

All density associations by vehicle type were higher than +0.83 except for the nonmotorized vehicles at $+0 \cdot 50$. A possible reason for a moderate correlation for non-motorized vehicles is that they use the highway area differently from motorized vehicles; they concentrate in a relatively narrow highway width along the road edge. Use of (2), proved valid in the three sites where non-homogeneous traffic prevailed.

It is tempting to compare observation-based $\bar{k}_{n} i$ to derive $\bar{k}_{n t}$. Although speeds remain relatively constant within each traffic entity type, they are not constant between different types of vehicles. A large average speed difference exists between non-motorized and motorized vehicle types. As mentioned earlier, one assumption regarding the use of Wardrop equation is that vehicular speeds are relatively constant, i.e., low coefficient of variation. The nonhomogeneous traffic density $\bar{k}_{n t}$ includes both motorized and non-motorized vehicle types whose average speeds are greatly different. A comparison between observed and predicted $\bar{k}_{n t}$ does not meet that assumption.

2.4a Wilcoxon signed-rank test between observed density and derived density: A nonparametric test, i.e., the Wilcoxon signed-rank test, compared between observed and derived densities. The Wilcoxon signed rank test does not make any distributional assumption of the data. At a $95 \%$ confidence level, no significant difference existed between observed and derived densities of light four-wheeler type, heavy vehicle type, motorized two-wheeler type, non-motorized two- and three-wheeler type, and cumulative density. Only in motorized three-wheeler type, the observed and derived densities were significantly different. In this comparison, speeds are relatively constant in the intra-traffic types. 
Table 1. Observed non-homogeneous traffic concentration.

\begin{tabular}{|c|c|c|c|c|c|c|c|}
\hline \multirow{2}{*}{$\begin{array}{l}\text { Site name } \\
\text { [length] } \\
\{\text { width }\}\end{array}$} & \multirow{2}{*}{$\begin{array}{c}\text { 5-minute } \\
\text { interval }\end{array}$} & \multicolumn{6}{|c|}{ Observed density, entities/(km-m) } \\
\hline & & $\mathrm{T} 1$ & Т 2 & T 3 & $\mathrm{~T} 4$ & T 5 & Total \\
\hline \multirow{12}{*}{$\begin{array}{l}\text { Panchsheel } \\
{[60.12 \mathrm{~m}]} \\
\{13.85 \mathrm{~m}\}\end{array}$} & 1 & 4.5 & $1 \cdot 1$ & 0.4 & 5.4 & 5.4 & $16 \cdot 8$ \\
\hline & 2 & $5 \cdot 1$ & 0.9 & 2.5 & $4 \cdot 3$ & $7 \cdot 2$ & 19.9 \\
\hline & 3 & $5 \cdot 6$ & 0.7 & 1.6 & 4.5 & 6.9 & $19 \cdot 2$ \\
\hline & 4 & 3.6 & $2 \cdot 2$ & 2.5 & 5.4 & $6 \cdot 7$ & $20 \cdot 4$ \\
\hline & 5 & 4.5 & 0.4 & $0 \cdot 3$ & 5.8 & 6.7 & 17.7 \\
\hline & 6 & $6 \cdot 0$ & $0 \cdot 2$ & $1 \cdot 8$ & 6.9 & 8.5 & 23.5 \\
\hline & 7 & $5 \cdot 1$ & 0.7 & 1.8 & $5 \cdot 6$ & 4.5 & 17.7 \\
\hline & 8 & 5.4 & 0.7 & $2 \cdot 0$ & 5.6 & 4.0 & 17.7 \\
\hline & 9 & 4.7 & 0.7 & 2.5 & 6.7 & $5 \cdot 1$ & 19.7 \\
\hline & 10 & 6.9 & 0.4 & $2 \cdot 5$ & $3 \cdot 4$ & 4.0 & $17 \cdot 2$ \\
\hline & 11 & $3 \cdot 6$ & 0.4 & 2.5 & $3 \cdot 8$ & $3 \cdot 6$ & 13.9 \\
\hline & 12 & $5 \cdot 4$ & 0.9 & $1 \cdot 3$ & $4 \cdot 3$ & $3 \cdot 8$ & $15 \cdot 7$ \\
\hline \multirow{12}{*}{$\begin{array}{l}\text { Defence } \\
\text { Colony } \\
{[42.08 \mathrm{~m}]} \\
\{10.62 \mathrm{~m}\}\end{array}$} & 1 & 7.6 & 1.4 & 0.9 & 3.8 & 1.3 & $15 \cdot 0$ \\
\hline & 2 & $7 \cdot 8$ & $1 \cdot 2$ & 1.9 & 6.5 & 2.5 & 19.8 \\
\hline & 3 & 5.5 & 0.9 & 3.4 & 4.7 & $1 \cdot 1$ & 15.7 \\
\hline & 4 & $8 \cdot 0$ & $1 \cdot 3$ & 3.9 & $6 \cdot 1$ & $1 \cdot 2$ & $20 \cdot 5$ \\
\hline & 5 & $6 \cdot 5$ & 1.8 & $3 \cdot 1$ & 7.4 & 1.8 & $20 \cdot 5$ \\
\hline & 6 & $5 \cdot 3$ & $1 \cdot 1$ & $3 \cdot 8$ & 8.4 & $2 \cdot 7$ & $21 \cdot 2$ \\
\hline & 7 & 5.5 & 0.4 & $3 \cdot 1$ & $5 \cdot 3$ & $1 \cdot 1$ & $15 \cdot 3$ \\
\hline & 8 & 7.9 & $0 \cdot 6$ & $2 \cdot 1$ & $4 \cdot 2$ & 1.4 & $16 \cdot 3$ \\
\hline & 9 & $6 \cdot 6$ & 0.9 & 4.0 & $5 \cdot 3$ & 1.5 & 18.4 \\
\hline & 10 & $7 \cdot 3$ & $1 \cdot 1$ & $3 \cdot 2$ & $4 \cdot 2$ & $1 \cdot 3$ & $17 \cdot 1$ \\
\hline & 11 & 5.5 & 1.2 & $2 \cdot 5$ & $3 \cdot 3$ & 0.7 & $13 \cdot 2$ \\
\hline & 12 & $7 \cdot 1$ & 0.7 & $2 \cdot 4$ & $3 \cdot 9$ & $0 \cdot 4$ & $14 \cdot 4$ \\
\hline \multirow{12}{*}{$\begin{array}{l}\text { Sundar } \\
\text { Nagar } \\
{[60 \cdot 77 \mathrm{~m}]} \\
\{10 \cdot 16 \mathrm{~m}\}\end{array}$} & 1 & 4.5 & 1.5 & $2 \cdot 8$ & $3 \cdot 5$ & $3 \cdot 2$ & 15.4 \\
\hline & 2 & $6 \cdot 1$ & 0.9 & 1.9 & $5 \cdot 1$ & $2 \cdot 3$ & $16 \cdot 3$ \\
\hline & 3 & 3.5 & $1 \cdot 3$ & 1.6 & 6.7 & 2.9 & 16.0 \\
\hline & 4 & $4 \cdot 2$ & $0 \cdot 6$ & 1.6 & $5 \cdot 2$ & 0.7 & 12.4 \\
\hline & 5 & $5 \cdot 2$ & 0.9 & $1 \cdot 2$ & 5.8 & $3 \cdot 2$ & $16 \cdot 3$ \\
\hline & 6 & $2 \cdot 3$ & 0.4 & 0.6 & $5 \cdot 5$ & $2 \cdot 8$ & 11.6 \\
\hline & 7 & $4 \cdot 2$ & $0 \cdot 6$ & 2.6 & 6.5 & $2 \cdot 0$ & $17 \cdot 0$ \\
\hline & 8 & $5 \cdot 2$ & 1.2 & $2 \cdot 6$ & $7 \cdot 3$ & $3 \cdot 8$ & $20 \cdot 1$ \\
\hline & 9 & $4 \cdot 1$ & 0.9 & 1.9 & $7 \cdot 6$ & $2 \cdot 8$ & $17 \cdot 2$ \\
\hline & 10 & 5.7 & $1 \cdot 3$ & $2 \cdot 2$ & $7 \cdot 1$ & $1 \cdot 3$ & 17.6 \\
\hline & 11 & $6 \cdot 1$ & 0.6 & 2.5 & 5.5 & 1.3 & $16 \cdot 0$ \\
\hline & 12 & $6 \cdot 3$ & 0.4 & $2 \cdot 3$ & $7 \cdot 3$ & $2 \cdot 0$ & $18 \cdot 3$ \\
\hline
\end{tabular}

${ }^{*} \mathrm{~T} 1=$ cars/vans/jeeps; $\mathrm{T} 2=$ trucks/buses/minibuses; $\mathrm{T} 3=$ motorized three-wheeler; $\mathrm{T} 4=$ motorized two-wheeler; $\mathrm{T} 5=$ non-motorized vehicle.

The association between observation-based density and density derived using the continuity equation was moderate to strong. The correlation with zero intercept ranged from $+0 \cdot 50$ to $+0 \cdot 90$. Wilcoxon signed-rank test compared observed and derived densities. At a $95 \%$ confidence level, no significant difference existed between observed and derived density of light four-wheeler type, heavy vehicle type, motorized two-wheeler type and non-motorized two- and three-wheeler type and total density. 
Table 2. Derived non-homogeneous traffic concentration.

\begin{tabular}{|c|c|c|c|c|c|c|c|}
\hline \multirow{2}{*}{$\begin{array}{l}\text { Site name } \\
\text { [length] } \\
\{\text { width }\}\end{array}$} & \multirow{2}{*}{$\begin{array}{l}\text { 5-minute } \\
\text { interval }\end{array}$} & \multicolumn{6}{|c|}{ Derived density, entities/(km-m) } \\
\hline & & T 1 & Т 2 & T 3 & T 4 & T 5 & Total \\
\hline \multirow{12}{*}{$\begin{array}{l}\text { Panchsheel } \\
{[60 \cdot 12 \mathrm{~m}]} \\
\{13.85 \mathrm{~m}\}\end{array}$} & 1 & $7 \cdot 0$ & 0.8 & 1.8 & $6 \cdot 5$ & $3 \cdot 2$ & 19.4 \\
\hline & 2 & $7 \cdot 2$ & 1.2 & 1.7 & $6 \cdot 1$ & $2 \cdot 3$ & 18.6 \\
\hline & 3 & 7.4 & 0.9 & $2 \cdot 1$ & $5 \cdot 3$ & $2 \cdot 0$ & 17.6 \\
\hline & 4 & $9 \cdot 1$ & 1.6 & 2.4 & $6 \cdot 2$ & $2 \cdot 0$ & $21 \cdot 3$ \\
\hline & 5 & $8 \cdot 3$ & 0.9 & 1.8 & $6 \cdot 4$ & $2 \cdot 0$ & 19.4 \\
\hline & 6 & 6.4 & 0.7 & 1.7 & 4.5 & $1 \cdot 3$ & 14.7 \\
\hline & 7 & 7.7 & 0.3 & $2 \cdot 3$ & $3 \cdot 8$ & $2 \cdot 2$ & $16 \cdot 3$ \\
\hline & 8 & $9 \cdot 1$ & 0.6 & $2 \cdot 4$ & $4 \cdot 3$ & 0.7 & $17 \cdot 2$ \\
\hline & 9 & $8 \cdot 1$ & 0.5 & $2 \cdot 3$ & $3 \cdot 6$ & 1.4 & $16 \cdot 0$ \\
\hline & 10 & $7 \cdot 3$ & 0.6 & $2 \cdot 0$ & $4 \cdot 1$ & 0.9 & 14.9 \\
\hline & 11 & $8 \cdot 2$ & 1.0 & $1 \cdot 8$ & 4.7 & 0.4 & $16 \cdot 0$ \\
\hline & 12 & $8 \cdot 3$ & $0 \cdot 6$ & 1.9 & $4 \cdot 1$ & $1 \cdot 1$ & $16 \cdot 1$ \\
\hline \multirow{12}{*}{$\begin{array}{l}\text { Defence } \\
\text { Colony } \\
{[42 \cdot 08 \mathrm{~m}]} \\
\{10.62 \mathrm{~m}\}\end{array}$} & 1 & $6 \cdot 9$ & 0.5 & $1 \cdot 3$ & 5.9 & 8.9 & 23.4 \\
\hline & 2 & 3.6 & 0.3 & 1.0 & $5 \cdot 2$ & 9.9 & $20 \cdot 0$ \\
\hline & 3 & $3 \cdot 0$ & 0.5 & 1.8 & 3.5 & $8 \cdot 0$ & 16.9 \\
\hline & 4 & $4 \cdot 1$ & $0 \cdot 3$ & 1.6 & 4.0 & 4.6 & 14.5 \\
\hline & 5 & $3 \cdot 0$ & 0.4 & 1.0 & $4 \cdot 1$ & 5.9 & 14.4 \\
\hline & 6 & $3 \cdot 3$ & 0.2 & $1 \cdot 1$ & $4 \cdot 2$ & $6 \cdot 9$ & $15 \cdot 7$ \\
\hline & 7 & $3 \cdot 0$ & $0 \cdot 2$ & 1.5 & $3 \cdot 7$ & $5 \cdot 8$ & 14.3 \\
\hline & 8 & 2.9 & $0 \cdot 3$ & 1.4 & $4 \cdot 1$ & 5.9 & 14.5 \\
\hline & 9 & $3 \cdot 2$ & 0.6 & 1.7 & 3.4 & $4 \cdot 1$ & $13 \cdot 0$ \\
\hline & 10 & $3 \cdot 5$ & 0.4 & 1.6 & 2.9 & 5.8 & $14 \cdot 1$ \\
\hline & 11 & $2 \cdot 5$ & 0.5 & 1.0 & $3 \cdot 0$ & 3.7 & $10 \cdot 7$ \\
\hline & 12 & $3 \cdot 6$ & $0 \cdot 3$ & $1 \cdot 0$ & 1.9 & 4.9 & $11 \cdot 7$ \\
\hline \multirow{12}{*}{$\begin{array}{l}\text { Sundar } \\
\text { Nagar } \\
{[60 \cdot 77 \mathrm{~m}]} \\
\{10 \cdot 16 \mathrm{~m}\}\end{array}$} & 1 & $3 \cdot 1$ & 2.4 & 1.6 & 8.2 & $2 \cdot 6$ & 17.8 \\
\hline & 2 & $5 \cdot 5$ & 0.9 & 1.6 & $11 \cdot 1$ & 4.0 & $23 \cdot 1$ \\
\hline & 3 & $3 \cdot 0$ & $1 \cdot 3$ & $1 \cdot 1$ & $10 \cdot 7$ & & $16 \cdot 2$ \\
\hline & 4 & $4 \cdot 1$ & 0.6 & 1.6 & $10 \cdot 0$ & $5 \cdot 8$ & $22 \cdot 1$ \\
\hline & 5 & $3 \cdot 3$ & 1.0 & $1 \cdot 1$ & $11 \cdot 2$ & 5.6 & $22 \cdot 2$ \\
\hline & 6 & 3.9 & 0.8 & 1.4 & $8 \cdot 0$ & & $14 \cdot 2$ \\
\hline & 7 & $7 \cdot 1$ & 1.4 & $2 \cdot 3$ & 13.5 & $10 \cdot 9$ & $35 \cdot 2$ \\
\hline & 8 & $6 \cdot 3$ & 0.8 & 1.9 & 14.0 & $10 \cdot 2$ & $33 \cdot 2$ \\
\hline & 9 & $6 \cdot 2$ & 0.9 & 1.8 & $10 \cdot 9$ & & 19.7 \\
\hline & 10 & $7 \cdot 5$ & 0.9 & 1.7 & $11 \cdot 8$ & & 21.9 \\
\hline & 11 & 8.5 & 0.8 & 1.9 & $10 \cdot 1$ & & 21.4 \\
\hline & 12 & $6 \cdot 6$ & $1 \cdot 1$ & 1.9 & $11 \cdot 6$ & 2.7 & 23.9 \\
\hline
\end{tabular}

${ }^{*} \mathrm{~T} 1=$ cars/vans/jeeps; T $2=$ trucks/buses/minibuses; T $3=$ motorized three-wheeler; $\mathrm{T} 4=$ motorized two-wheeler; T $5=$ non-motorized vehicle.

\subsection{Summary}

Our experiment shows that the continuity equation is also valid under non-homogeneous conditions. The basic difference between homogeneous and non-homogeneous traffic is in the use of road space. For homogeneous traffic where car-following and lane discipline behaviour prevail, all traffic entities use an equal lane width. Traffic concentrations are in units of vehicles/km or vehicles/mi. However, in non-homogeneous traffic, loose lane discipline prevails with no strict car-following logic. An adjustment to reflect non-homogeneous traffic 
characteristics modified the original Wardrop equation. Each type of vehicle has an average concentration in the highway area. The concentration measurement is the average number of traffic entities of type $j$ per unit area of highway, e.g., motorized two-wheelers/(km.m) or motorized three-wheelers/(mi.ft).

Quantifying non-homogeneous traffic measures revealed several insights. The sum of densities of each traffic entity type comprising non-homogeneous traffic on a given street area is the density of non-homogeneous traffic in the same street area. The sum of every flow of traffic entity type measured across the width of the street area during 5-minutes is nonhomogeneous traffic flow given the same street width and duration. Finally, the space mean speed of non-homogeneous traffic is the weighted harmonic speed of each traffic type's space mean speed.

The association between observation-based density and density derived using the continuity equation was moderate to strong. The correlation with zero intercept ranged from +0.50 to $+0 \cdot 90$. Wilcoxon signed-rank test compared observed and derived densities. At a $95 \%$ confidence level, no significant difference existed between observed and derived density of light four-wheeler type, heavy vehicle type, motorized two-wheeler type and non-motorized two- and three-wheeler type and the cumulative of all, viz total density.

\section{Passenger car units for non-homogeneous traffic using a modified density method}

Many methods exist for determining passenger-car equivalents (PCEs), passenger-car units (PCUs) or the homogenization coefficient: the semi-empirical method, Walker's method, headway method, multiple linear regression method, and the simulation method (CRRI, 1982; Kadiyali \& Viswanathan 1992). In the homogenization coefficient method, comparing theoretical maximum capacities when different vehicle types exclusively use the road produces PCUs. The method compares the 'all passenger-car' and 'all other than passenger car type' capacity of traffic lanes. Walker's method (Cunagin \& Messer 1982) bases PCUs on overtakings that the traffic type would perform per kilometer length of highway if each vehicle continued at its normal speed. The ratio of overtakings when traffic has one slow-moving vehicle per hour to overtakings when traffic has passenger cars of equal volume calculates passenger-car units. The concept that a heavy vehicle occupies more space than a passenger car and reduces capacity forms the basis of the headway method. Analysis of time headways of a single stream of vehicles in a platoon during congested conditions can determine capacity-based PCUs. However, calculating PCUs based on the ratio of headways does not produce straightforward results; several approaches for determining headways exist. Plots of spacing versus headway can generate PCUs. Similarly, a plot of speed versus headways of individual vehicles by entering curves at constant speeds can calculate PCUs (McShane, \& Roess 1990). Bang et al (1998) have estimated PCUs for road links and township roads in China using the regression method. Regression analyses produced speed-based PCUs using 5-minute, average speed and flow data from sites with sufficient flows to show a significant speed reduction at increasing flow. The relative effect of different vehicle types in a mixed traffic flow on the speed of light vehicles serves as a criterion for equivalence. The analysis of the ratio between the regression coefficient for a specific vehicle type and that for light vehicles produced final PCU values. Bang et al (1995) developed a simulation method for determining PCUs using the VTI simulation model. The simulation method produces PCU values through successive simulations studying the impact on light vehicle speed at the introduction of other vehicle types in the traffic stream. 
Table 3. Highway widths.

\begin{tabular}{lcc}
\hline Highway type & $\begin{array}{c}\text { Pavement width } \\
\text { in meters }\end{array}$ & $\begin{array}{c}\text { Shoulder width } \\
\text { in meters }\end{array}$ \\
\hline Single lane & 3.7 & 1.5 \\
Intermediate lane & 5.5 & 1.5 \\
Two lanes without paved shoulders & 7.0 & 1.5 \\
Two lanes with $1.5 \mathrm{~m}$ shoulders & 7.5 & 1.5 \\
Two lanes with $2.5 \mathrm{~m}$ shoulders & 7.5 & 2.5 \\
Four-lanes divided & 7.5 & 1.5 \\
\hline
\end{tabular}

Webster and Elefteriadou (1999) estimated passenger-car equivalents for heavy vehicles using simulation based on traffic density. The study investigated the effect of several characteristics related to freeway design, vehicle performance, and the traffic stream on passenger-car equivalents for heavy vehicles. Traffic density proves a good indicator of the driver's freedom to maneuver, an accurate measure of proximity to other vehicles, and consistent with the measures of effectiveness for freeways and multi-lane highways used in the Highway Capacity Manual (HCM, 2000). New PCU values in HCM 2000 stem from Webster's and Elefteriadou's work. PCU values derived from the density method use underlying homogeneous traffic concepts such as strict lane discipline, car following logic, and a vehicle fleet whose elements do not vary much in physical dimensions. Homogeneous traffic represents a very narrow case of heterogeneous traffic. Indian highways carry non-homogeneous traffic, which often includes non-motorized traffic entities. Loose lane discipline prevails; lane driving and car following is not the norm. Methods based on homogeneous traffic concepts have limited applicability for this non-homogeneous traffic.

\subsection{Methodology}

The modified density method proved most applicable because it used field data collected from National Highway and State Highway sites in India. Speed, flow, and lateral roadway position data came from 34 rural and suburban highway sites throughout India. These sites comprised six highway types with two roadside development characteristics: (a) single lane type at three rural sites and one suburban site; (b) intermediate or 1.5 lane type at three rural sites and three suburbans; (c) two lanes without paved shoulders type at three rural sites and three suburbans; (d) two lanes with $1.5 \mathrm{~m}(5 \mathrm{ft})$ paved shoulders type at two rural sites and

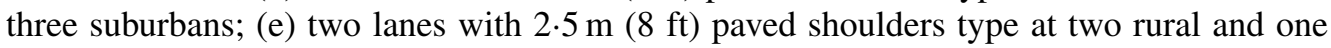
suburban; and (f) four-lanes divided type at five rural sites and five suburban developments. Table 3 shows the travelled width and shoulder width of each highway type. Since most non-homogeneous traffic does not use marked delineated lanes, if present, on the pavement surface, one must modify the density method to account for heterogeneity. This modification adds the spatial dimension of width to the traditional density method. Incorporating the width dimension into the density method allows a more accurate quantification of non-homogeneous traffic characteristics.

For estimating PCU values using the modified density method, all traffic entities that comprised non-homogeneous traffic at 34 Indian highway sites had an assignment into one of eight traffic types. Traffic entity operational characteristics define the traffic types. Traffic entities associated with each type are: (a) heavy vehicle (HV) type containing buses, singleunit trucks, and trailer trucks; (b) light commercial vehicle (LCV) type for mini-trucks, light 
(A)

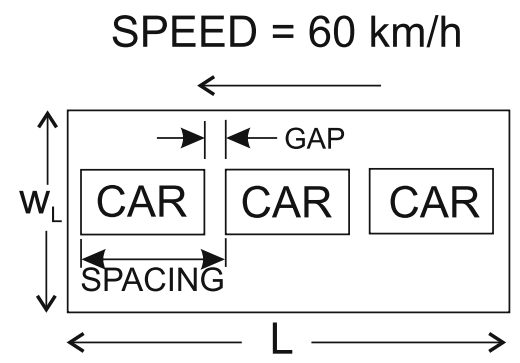

(B)

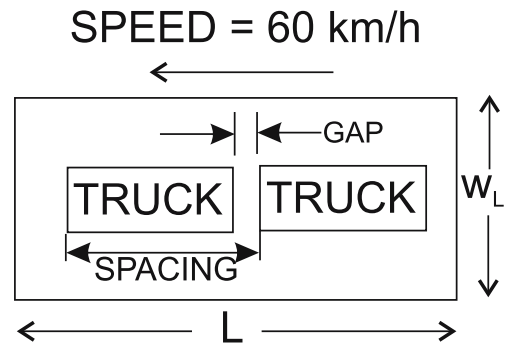

Figure 3. PCU estimation using homogeneous traffic.

pick-up trucks, and minibuses; (c) tractor (TRAC) type for tractors, farm-equipment vehicles, and construction-equipment vehicles; (d) passenger car (PC) type for cars, jeeps, and vans; (e) motorized two-wheeler (M2W) type for motor scooters, motorcycles, and mopeds; (f) motorized three-wheeler (M3W) type for autorickshaws and tempos; (g) non-motorized two-wheeler (NM2W) type for bicycles; and (h) other non-motorized entity (ONME) type for pedestrians, human powered carts, animals, animal carts, and pedal rickshaws. The weighted width of HVs is $2.5 \mathrm{~m}(8.2 \mathrm{ft})$. LCVs had a weighted width of $2.15 \mathrm{~m}(7.0 \mathrm{ft})$. For TRACs, the width was $1.8 \mathrm{~m}(5.9 \mathrm{ft})$. PCs were $1.5 \mathrm{~m}(4.9 \mathrm{ft})$ wide. The remaining widths were $0.78 \mathrm{~m}$ $(2.6 \mathrm{ft})$ for M2Ws, $1.35 \mathrm{~m}$ ( $4.4 \mathrm{ft})$ for M3Ws, $0.65 \mathrm{~m}(2.1 \mathrm{ft})$ for NM2Ws, and $1.00 \mathrm{~m}(3.3 \mathrm{ft})$ for ONMEs.

Figure 3 illustrates the traditional density method used for homogeneous traffic. A base traffic mixture of only passenger cars becomes equivalent with another 100 percent, homogeneous, traffic stream. This other homogeneous traffic stream consists only of another traffic entity type such as heavy vehicles or recreational vehicles. The space mean speed of the passenger-car traffic stream is $60 \mathrm{~km} / \mathrm{h}$ in figure 3(A). This speed implies that passenger cars will maintain a specific, average gap. As mean passenger-car speed changes, the average spacing changes, i.e., traffic concentration or density. Average spacing is the inverse of density, i.e.,

$$
\bar{h}_{\text {space }}=1 / k,
$$

where $k$ is density in traffic entities per kilometer (entities/mi), and $\bar{h}_{\text {space }}$ is the average frontbumper to front-bumper spacing in kilometers (mi).

Figure 3(B) has the same highway lane width and length as figure 3(A). It also has the same geometric and environmental conditions. However, figure 3(B) has 100\% heavy vehicles in its traffic stream. Passenger-car and heavy vehicle streams have equal space mean speeds when using the density method. The relationship between heavy vehicle density and passenger car density derives PCUs for heavy vehicles:

$$
\mathrm{PCU}_{\mathrm{HHV}}=\frac{k_{\mathrm{Hpc}} / W_{\mathrm{Lpc}}}{k_{\mathrm{HHV}} / W_{\mathrm{LHV}}},
$$

where $k_{\mathrm{HHV}}$ is heavy vehicle density in a pure homogeneous traffic stream in heavy vehicles per kilometer $(\mathrm{HV} / \mathrm{mi}), W_{\mathrm{LHV}}$ is the highway lane width that heavy vehicles use in homogeneous traffic in meters (ft), $k_{\mathrm{Hpc}}$ is the passenger-car density in a pure homogeneous traffic stream in passenger cars per kilometer ( $\mathrm{pc} / \mathrm{mi}), W_{\mathrm{Lpc}}$ is the highway lane width that passenger cars 


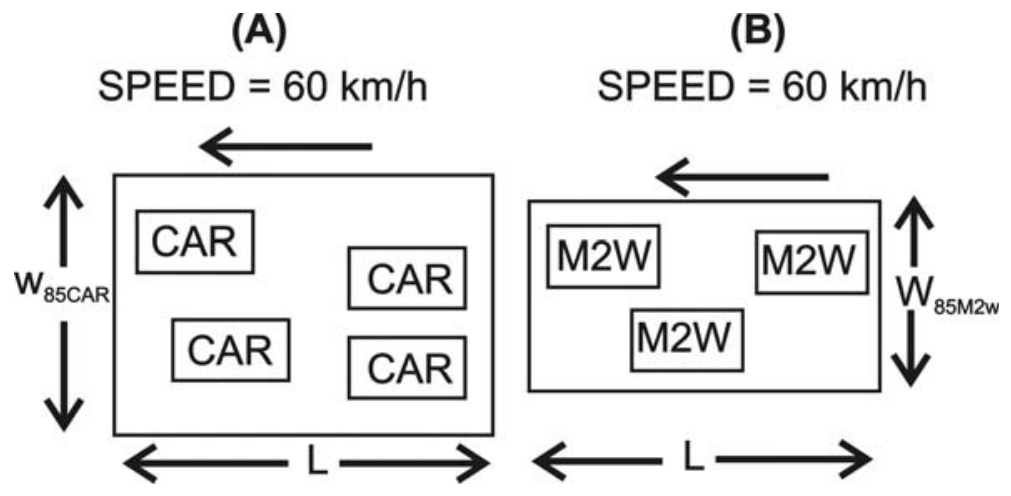

Figure 4. PCU estimation using non-homogeneous traffic.

use in homogeneous traffic, and $\mathrm{PCU}_{\mathrm{HHV}}$ is the passenger-car unit for heavy vehicles given homogeneous traffic behaviour in passenger-cars per heavy vehicle. In the density-based PCU method for homogeneous traffic where car-following and strict lane-discipline behaviour prevails, all traffic entities use an equal highway lane width. In the above example, $W_{\mathrm{Lpc}}$ equals $W_{\mathrm{LHV}}$.

The average spacing or density of heavy vehicles changes depending on the grade and length of the grade according to the US Highway Capacity Manual (HCM, 2000). For uniform upgrades, $\mathrm{PCU} \mathrm{HHV}_{\mathrm{HH}}$ or $E_{T}$ may go as high as 7.0 passenger cars per heavy vehicle. On uniform downgrades, $\mathrm{PCU}_{\mathrm{HHV}}$ can go as high as 7.5 passenger cars per heavy vehicle. On level terrain, the effect of grade and grade length becomes negligible. For level terrain and similar space mean speeds, average heavy vehicle gap approximately equals the average passenger-car gap because the operational characteristics between heavy vehicles and passenger cars on level terrain at a constant speed become approximately the same. Given these assumptions, it follows:

$$
\mathrm{PCU}_{\mathrm{HHV}}=L_{\mathrm{HV}} / L_{\mathrm{pc}}
$$

where $L_{\mathrm{pc}}$ is the average length of passenger cars in meters ( $\mathrm{ft}$ ), and $L_{\mathrm{HV}}$ is the average length of heavy vehicles in meters ( $\mathrm{ft}$ ). In the US homogeneous traffic, the minimum PCU value is 1.5 for heavy vehicles on level terrain as roughly shown in figure 1 (HCM 2000).

Similarly, figure 4 illustrates the non-homogeneous traffic conditions on Indian National Highways and State Highways in rural and suburban areas. One characterizes nonhomogeneous traffic as having lane discipline that is relaxed or 'loose'. Complicated lateral position changing and car-following behaviour also characterizes non-homogeneous traffic conditions. Non-homogeneous traffic meets two conditions. One condition is that the peakhour volume has less than $85 \%$ passenger-cars. The other one is that the peak-hour volume has less than $90 \%$ cars, trucks, and buses (Fazio \& Tiwari 1995).

One can modify the density method to adjust for traffic heterogeneity in PCU calculations by making figure 3(A) equivalent to figure 3(B). In most non-homogeneous traffic streams, passenger cars do not use highway width as in homogeneous traffic. Traffic entities of similar speed and size pre-segregate into a natural distribution across the pavement width. One determines these distribution widths by traffic entity type from field observations. From these distributions, one calculates the 85th percentile highway widths $\left(W_{85 j}\right)$ that each traffic entity type $(j)$ uses. These highway width distributions depend on the observed lateral position of 
Table 4. Road width used by traffic entity types.

\begin{tabular}{|c|c|c|c|c|c|c|c|c|}
\hline \multirow[b]{2}{*}{ Highway type } & \multicolumn{8}{|c|}{ 85th Percentile highway width, $W_{85 j}$, in meters } \\
\hline & HV & LCV & TRAC & $\mathrm{PC}$ & $\mathrm{M} 2 \mathrm{~W}$ & M3W & NM2W & ONME \\
\hline Single lane & $5 \cdot 50$ & $5 \cdot 15$ & $3 \cdot 30$ & $4 \cdot 50$ & $2 \cdot 78$ & $4 \cdot 85$ & $5 \cdot 15$ & $7 \cdot 00$ \\
\hline Intermediate lane & $5 \cdot 50$ & $5 \cdot 15$ & $5 \cdot 80$ & $5 \cdot 00$ & $4 \cdot 28$ & $5 \cdot 35$ & $5 \cdot 65$ & $1 \cdot 00$ \\
\hline $\begin{array}{l}\text { Two lanes without paved } \\
\text { shoulders }\end{array}$ & $4 \cdot 50$ & $4 \cdot 60$ & $4 \cdot 30$ & $3 \cdot 50$ & $3 \cdot 28$ & $3 \cdot 35$ & $3 \cdot 63$ & $3 \cdot 00$ \\
\hline $\begin{array}{l}\text { Two lanes with } 1.5 \mathrm{~m} \\
\text { shoulders }\end{array}$ & $4 \cdot 50$ & $4 \cdot 15$ & $3 \cdot 30$ & $3 \cdot 50$ & $2 \cdot 78$ & $2 \cdot 87$ & $2 \cdot 15$ & $4 \cdot 48$ \\
\hline $\begin{array}{l}\text { Two lanes with } 2.5 \mathrm{~m} \\
\text { shoulders }\end{array}$ & $6 \cdot 00$ & $5 \cdot 15$ & $5 \cdot 80$ & $4 \cdot 50$ & 4.78 & $5 \cdot 35$ & $6 \cdot 15$ & $6 \cdot 50$ \\
\hline Four-lanes divided & $8 \cdot 00$ & $2 \cdot 65$ & $7 \cdot 80$ & $5 \cdot 50$ & $6 \cdot 78$ & $6 \cdot 35$ & 5.65 & 3.00 \\
\hline
\end{tabular}

the left front tire of the traffic entity measured along a lateral line across the highway and shoulders if present. The distributions' median position also depended on the average width of the traffic entity type. Sampling these widths in the field produced the weighted average values.

The 85th percentile width used by Indian traffic entities allowed density derivation over a highway area instead of just length. Table 4 shows the 85 th percentile width that each Indian traffic entity type used. The 85 th percentile width is the width utilized by $85 \%$ of entities comprising the traffic entity type. Field data produced forty-eight such distributions based on a two-dimensional matrix of six highway types $(k)$ by eight traffic entity types $(j)$.

Figure 5 shows one such distribution involving the motorized two-wheeler group on a fourlanes, divided highway. Twenty-three of the 48 distributions showed that the rate of change stabilized at the 85th percentile distribution width. This 85 th percentile highway width is the roadway width that each traffic entity type effectively uses. The highway width used by $85 \%$ of the entities may exceed total pavement width because vehicles do not necessarily follow marked lanes and may move sometimes on shoulders or space available beyond shoulders.

Holding space mean speeds equal, the $100 \%$ homogeneous traffic stream of passenger cars can have a higher or lower unit area density than passenger cars in non-homogeneous traffic because the 85 th percentile width that non-homogeneous passenger cars use can be wider

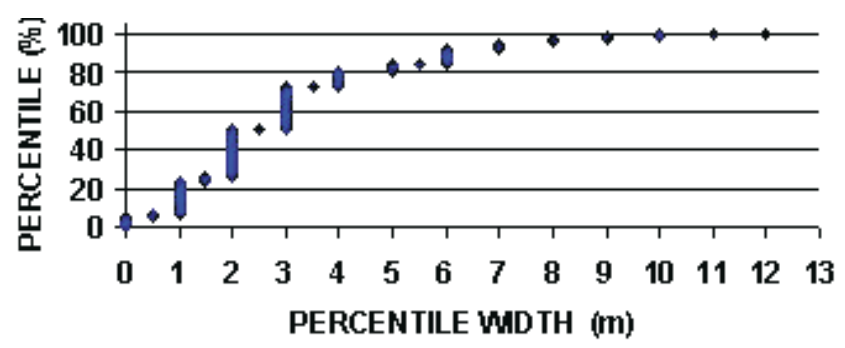

Figure 5. Percentile pavement width distribution of M2W type on four-lanes divided highways. 
Table 5. Space mean speeds.

\begin{tabular}{|c|c|c|c|c|c|c|c|c|}
\hline \multirow[b]{2}{*}{ Highway type } & \multicolumn{8}{|c|}{ Space mean speed, $\bar{u}_{j}$, in $\mathrm{km} / \mathrm{h}$} \\
\hline & HV & LCV & TRAC & PC & $\mathrm{M} 2 \mathrm{~W}$ & M3W & $\mathrm{NM} 2 \mathrm{~W}$ & ONME \\
\hline Single lane & $33 \cdot 6$ & $33 \cdot 1$ & $28 \cdot 0$ & $43 \cdot 4$ & $35 \cdot 2$ & $29 \cdot 3$ & $10 \cdot 9$ & NA \\
\hline Intermediate lane & $37 \cdot 5$ & $31 \cdot 2$ & $23 \cdot 6$ & $37 \cdot 2$ & $27 \cdot 3$ & $27 \cdot 9$ & $13 \cdot 9$ & NA \\
\hline $\begin{array}{l}\text { Two lanes without paved } \\
\text { shoulders }\end{array}$ & $46 \cdot 8$ & $39 \cdot 6$ & $20 \cdot 2$ & $53 \cdot 8$ & $43 \cdot 0$ & 29.9 & $13 \cdot 5$ & NA \\
\hline $\begin{array}{l}\text { Two lanes with } 1.5 \mathrm{~m} \\
\text { shoulders }\end{array}$ & $41 \cdot 4$ & $21 \cdot 9$ & $25 \cdot 9$ & $52 \cdot 2$ & $36 \cdot 7$ & $29 \cdot 7$ & $12 \cdot 6$ & NA \\
\hline $\begin{array}{l}\text { Two lanes with } 2.5 \mathrm{~m} \\
\text { shoulders }\end{array}$ & $52 \cdot 2$ & $43 \cdot 5$ & $15 \cdot 9$ & $55 \cdot 5$ & $38 \cdot 4$ & $34 \cdot 2$ & $14 \cdot 3$ & $6 \cdot 8$ \\
\hline Four-lanes divided & $51 \cdot 5$ & $50 \cdot 8$ & $22 \cdot 4$ & $62 \cdot 5$ & $38 \cdot 5$ & $31 \cdot 1$ & $13 \cdot 9$ & $9 \cdot 0$ \\
\hline
\end{tabular}

or narrower than a base $3.7 \mathrm{~m}(12 \mathrm{ft})$ lane. Making passenger cars in homogeneous traffic equivalent to passenger cars in non-homogeneous traffic produces the following relationship:

$$
\left[f_{\mathrm{PCU}}\right]_{k}=\left[\frac{k_{\mathrm{pc}} / W_{\mathrm{Lpc}}}{k_{\mathrm{pc}} / W_{85 \mathrm{pc}}}\right]_{k}
$$

where, for highway type $k, k_{\mathrm{pc}}$ is the concentration of passenger cars in passenger cars per kilometer ( $\mathrm{pc} / \mathrm{mi}$ ), $W_{85 \mathrm{pc}}$ is the 85 th percentile highway width that passenger cars use in meters (ft), $W_{\mathrm{Lpc}}$ is the base $3.7 \mathrm{~m}(12 \mathrm{ft})$ lane width for passenger cars in homogeneous traffic conditions, and $f_{\mathrm{PCU}}$ becomes the passenger-car-unit, adjustment factor to translate nonhomogeneous-based PCUs into homogeneous-based PCUs.

To determine PCU values for non-homogeneous Indian conditions, traffic entity types other than passenger car became equivalent to Indian passenger cars. Translating this equivalence using measures from Indian field data yields the following relationship:

$$
\left[\mathrm{PCU}_{j}\right]_{k}=\left[\frac{k_{\mathrm{pc}} / W_{85 p c}}{\left(q_{j} / \bar{u}_{j}\right) / W_{85 j}}\right]_{k}
$$

where, for highway type $k, q_{j}$ is the non-homogeneous flow of non-passenger car entity type $j$ in entities per hour, $\bar{u}_{j}$ represents the space mean speed of non-passenger car type $j$ in kilometers per hour $(\mathrm{mi} / \mathrm{h}), W_{85 j}$ is the 85 th percentile highway width that non-passenger car type $j$ uses in meters ( $\mathrm{ft}$ ), and $\mathrm{PCU}_{j}$ is the passenger-car unit for traffic type $j$ in Indian passenger cars per $j$.

Videotapes rendered traffic characteristics like volume, speed, and density for each entity type on the six different highway types. Table 5 gives entity type space mean speed. Table 6 lists the densities of the entity types during the peak hour. The number of entities per kilometer (mi) in the hour of maximum flow on the highway during three hours of a peak period defined density in the peak hour.

The modified density method requires comparison of density of traffic entity types at the same space mean speed of passenger cars. Table 7 gives adjusted densities at the passengercar space mean speed on the site. One derives this estimation by plotting car density versus car 
Table 6. Peak hour traffic concentrations.

\begin{tabular}{lcccccccc}
\hline & \multicolumn{7}{c}{ Traffic density, $k_{j}$, in entities/km } \\
\cline { 2 - 9 } Highway type & HV & LCV & TRAC & PC & M2W & M3W & NM2W & ONME \\
\hline Single lane & 0.36 & 0.14 & 0.05 & 0.12 & 0.81 & 0.11 & 0.31 & 0.00 \\
$\begin{array}{l}\text { Intermediate lane } \\
\begin{array}{l}\text { Two lanes without paved } \\
\quad \text { shoulders }\end{array}\end{array}$ & 0.71 & 0.13 & 0.50 & 0.49 & 1.03 & 0.32 & 1.26 & 0.00 \\
$\begin{array}{l}\text { Two lanes with 1.5 m } \\
\text { shoulders }\end{array}$ & 3.62 & 0.91 & 0.25 & 2.56 & 1.48 & 2.23 & 3.31 & 0.40 \\
$\begin{array}{l}\text { Two lanes with 2.5 m } \\
\text { shoulders }\end{array}$ & 2.22 & 0.70 & 0.42 & 4.05 & 3.68 & 0.45 & 3.00 & 0.93 \\
$\begin{array}{l}\text { Four-lanes divided } \\
\quad 2.05\end{array}$ & 0.67 & 0.72 & 2.33 & 2.13 & 0.44 & 1.89 & 0.43 \\
\hline
\end{tabular}

speed graph and interpolating the density at the corresponding average speed of other traffic groups. The density of other non-motorized entities becomes very small primarily because these entities do not use the paved shoulders or pavement. For some highway types, one could not calculate the density values for other non-motorized vehicles due to insufficient sample size. Table 8 shows density adjustment to unit area of road in entities per kilometer*meter (entities/(mi*ft)).

Most importantly, approximately equal space mean speeds determine the unit area densities in the equations. One calculates passenger-car density from the ratio of the passenger-car flow for the highway type to passenger-car space mean speed. Division of this density value by the standard lane width that passenger cars use in homogeneous traffic, i.e., $3.7 \mathrm{~m} \mathrm{(12 \textrm {ft } )}$ produces the density-lane width ratio $\left(k_{\mathrm{pc}} / W_{\mathrm{Lpc}}\right)$ as shown in table 9 . Table 10 shows unit

Table 7. Traffic concentration forecasts at passenger car space mean speeds.

\begin{tabular}{lcccccccc}
\hline & \multicolumn{7}{c}{ Traffic density, $k_{j}$, in entities/km } \\
\cline { 2 - 8 } Highway type & HV & LCV & TRAC & PC & M2W & M3W & NM2W & ONME \\
\hline Single lane & 0.20 & 0.20 & 0.24 & 0.12 & 0.19 & 0.23 & 0.38 & NA \\
$\begin{array}{l}\text { Intermediate lane } \\
\begin{array}{l}\text { Two lanes without paved } \\
\text { shoulders }\end{array}\end{array}$ & 0.49 & 0.49 & 0.49 & 0.49 & 0.49 & 0.49 & 0.48 & NA \\
$\begin{array}{l}\text { Two lanes with 1.5 m } \\
\quad \text { shoulders }\end{array}$ & 4.41 & 7.10 & 6.54 & 2.56 & 5.06 & 6.02 & 8.37 & 4.89 \\
$\begin{array}{l}\text { Two lanes with 2.5 m } \\
\text { shoulders }\end{array}$ & 4.62 & 6.19 & 11.12 & 4.05 & 7.10 & 7.85 & 11.4 & 12.74 \\
\begin{tabular}{l} 
Four-lanes divided \\
\hline
\end{tabular} & 2.91 & 2.95 & 4.61 & 2.33 & 3.67 & 4.10 & 5.11 & 5.40 \\
\hline
\end{tabular}


Table 8. Unit area concentration using 85th percentile road width used.

\begin{tabular}{lcccccccc}
\hline & \multicolumn{7}{c}{ Traffic density, $k_{j} / W_{85 J}$, in entities/(km*m) } \\
\cline { 2 - 9 } Highway type & HV & LCV & TRAC & PC & M2W & M3W & NM2W & ONME \\
\hline Single lane & 0.07 & 0.03 & 0.01 & 0.03 & 0.04 & 0.17 & 0.06 & 0.00 \\
$\begin{array}{l}\text { Intermediate lane } \\
\begin{array}{l}\text { Two lanes without paved } \\
\quad \text { shoulders }\end{array}\end{array}$ & 0.13 & 0.03 & 0.09 & 0.10 & 0.07 & 0.19 & 0.22 & 0.00 \\
$\begin{array}{l}\text { Two lanes with 1.5 m } \\
\text { shoulders }\end{array}$ & 0.80 & 0.08 & 0.29 & 0.31 & 0.06 & 0.45 & 0.71 & 0.00 \\
$\begin{array}{l}\text { Two lanes with 2.5 m } \\
\quad \text { shoulders }\end{array}$ & 0.37 & 0.14 & 0.07 & 0.90 & 0.09 & 0.69 & 0.49 & 0.14 \\
$\begin{array}{l}\text { Four-lanes divided } \\
\quad\end{array}$ & 0.26 & 0.25 & 0.09 & 0.42 & 0.07 & 0.34 & 0.33 & 0.14 \\
\hline
\end{tabular}

Table 9. Passenger car unit area concentration using homogeneous traffic lane width.

\begin{tabular}{lc}
\hline Highway type & $k_{\mathrm{pc}} / W_{\mathrm{Lpc}} \mathrm{pc} /\left(\mathrm{km}^{*} \mathrm{~m}\right)$ \\
\hline Single lane & 0.03 \\
Intermediate lane & 0.13 \\
Two lanes without paved shoulders & 0.29 \\
Two lanes with $1.5 \mathrm{~m}$ shoulders & 0.69 \\
Two lanes with $2.5 \mathrm{~m}$ shoulders & 1.09 \\
Four-lanes divided & 0.63 \\
\hline
\end{tabular}

Table 10. Unit area concentration forecasts at passenger car space mean speeds.

\begin{tabular}{lcccccccc}
\hline & \multicolumn{6}{c}{ Traffic density, $k_{j} / W_{85 J}$, in entities/(km*m) } \\
\cline { 2 - 8 } Highway type & HV & LCV & TRAC & PC & M2W & M3W & NM2W & ONME \\
\hline Single lane & 0.04 & 0.05 & 0.05 & 0.03 & 0.04 & 0.05 & 0.08 & NA \\
$\begin{array}{l}\text { Intermediate lane } \\
\begin{array}{c}\text { Two lanes without } \\
\text { shoulders }\end{array}\end{array}$ & 0.10 & 0.10 & 0.10 & 0.10 & 0.10 & 0.10 & 0.10 & NA \\
$\begin{array}{l}\text { Two lanes with 1.5 m } \\
\text { shoulders }\end{array}$ & 1.26 & 2.03 & 1.87 & 0.84 & 1.45 & 1.72 & 2.39 & 1.40 \\
$\begin{array}{l}\text { Two lanes with 2.5 m } \\
\text { shoulders }\end{array}$ & 1.03 & 1.38 & 2.47 & 0.90 & 1.58 & 1.74 & 2.53 & 2.83 \\
\begin{tabular}{l} 
Four-lanes divided \\
\hline
\end{tabular} & 0.53 & 0.54 & 0.84 & 0.41 & 0.67 & 0.75 & 0.93 & 0.98 \\
\hline
\end{tabular}


Table 11. Non-homogeneous passenger car units.

\begin{tabular}{|c|c|c|c|c|c|c|c|c|}
\hline \multirow[b]{2}{*}{ Highway type } & \multicolumn{8}{|c|}{$\mathrm{PCU}_{j}$ in $\mathrm{pc} / j$} \\
\hline & $\mathrm{HV}$ & LCV & TRAC & $\mathrm{PC}$ & $\mathrm{M} 2 \mathrm{~W}$ & M3W & NM2W & ONME \\
\hline Single lane & 0.67 & 1.72 & 3.75 & $1 \cdot 00$ & $0 \cdot 25$ & $1 \cdot 34$ & $1 \cdot 39$ & NA \\
\hline Intermediate lane & $0 \cdot 77$ & $3 \cdot 88$ & $1 \cdot 14$ & $1 \cdot 00$ & $0 \cdot 51$ & $1 \cdot 31$ & 0.44 & NA \\
\hline $\begin{array}{l}\text { Two lanes without } \\
\text { paved shoulders }\end{array}$ & $1 \cdot 11$ & $5 \cdot 52$ & $2 \cdot 18$ & $1 \cdot 00$ & $0 \cdot 91$ & $9 \cdot 16$ & 0.97 & NA \\
\hline $\begin{array}{l}\text { Two lanes with } 1.5 \mathrm{~m} \\
\text { shoulders }\end{array}$ & 1.57 & $9 \cdot 21$ & $24 \cdot 47$ & $1 \cdot 15$ & $2 \cdot 81$ & $2 \cdot 15$ & 1.55 & $15 \cdot 65$ \\
\hline $\begin{array}{l}\text { Two lanes with } 2.5 \mathrm{~m} \\
\text { shoulders }\end{array}$ & $2 \cdot 77$ & $10 \cdot 17$ & $33 \cdot 84$ & $1 \cdot 00$ & $2 \cdot 29$ & $18 \cdot 66$ & $5 \cdot 20$ & $19 \cdot 86$ \\
\hline Four-lanes divided & $2 \cdot 06$ & $2 \cdot 14$ & $9 \cdot 10$ & 0.97 & 1.99 & 11.44 & $2 \cdot 77$ & $6 \cdot 91$ \\
\hline
\end{tabular}

area density after adjustment to equal passenger-car space mean speed using 85 th percentile highway width $\left(k_{j} / W_{85 j}\right\}$.

\subsection{Results}

Table 11 shows the Indian PCU values derived using (16) and the values in table 9 and table 10. Table 12 gives the share of each traffic entity type on the road. Table 13 gives the passenger-car adjustment factor, $f_{\mathrm{PCU}}$, to allow conversion between non-homogeneous traffic and homogeneous traffic. Equation (15), tables 9 and 10 produced the $f_{\mathrm{PCU}}$ values.

The results in table 11 show that as highway width varies and as on-coming and internal traffic friction influences spacing, significant differences among the Indian highway types occur. Passenger cars tend to occupy more space on highways that have greater widths. Lesser

Table 12. Percent traffic composition.

\begin{tabular}{lcccccccc}
\hline & \multicolumn{7}{c}{ Percent composition in \% } \\
\cline { 2 - 9 } Highway type & HV & LCV & TRAC & PC & M2W & M3W & NM2W & ONME \\
\hline Single lane & 19 & 7 & 3 & 6 & 43 & 6 & 16 & 0 \\
$\begin{array}{l}\text { Intermediate lane } \\
\begin{array}{l}\text { Two lanes without paved } \\
\text { shoulders }\end{array}\end{array}$ & 16 & 3 & 11 & 11 & 23 & 7 & 28 & 0 \\
$\begin{array}{l}\text { Two lanes with 1.5 m } \\
\text { shoulders }\end{array}$ & 25 & 6 & 2 & 17 & 10 & 15 & 22 & 3 \\
$\begin{array}{l}\text { Two lanes with 2.5 m } \\
\quad \text { shoulders }\end{array}$ & 14 & 5 & 3 & 26 & 24 & 3 & 19 & 6 \\
\begin{tabular}{l} 
Four-lanes divided \\
\hline
\end{tabular} & 19 & 6 & 7 & 22 & 20 & 4 & 18 & 4 \\
\hline
\end{tabular}


Table 13. Passenger car unit adjustment factor.

\begin{tabular}{lc}
\hline Highway type & $f_{\mathrm{PCU}}$ \\
\hline Single lane & 1.22 \\
Intermediate lane & 1.35 \\
Two lanes without paved shoulders & 0.95 \\
Two lanes with $1.5 \mathrm{~m}$ shoulders & 0.95 \\
Two lanes with $2.5 \mathrm{~m}$ shoulders & 1.22 \\
Four-lanes divided & 1.49 \\
\hline
\end{tabular}

width forces passenger cars to form tighter 85th percentile widths and hence occupy less space. Not only do the passenger cars occupy more area on wider highways, but also other entity types do so as is evident from the higher PCU value on wider highways as compared to single lane highways. The share of each traffic type present on the road explains the variation in PCU values for different traffic types.

Tables 11 and 12 show very high PCU values for tractors when the share of tractors is below $3 \%$ of the total traffic. Similarly, PCU values of motorized three-wheelers also have very high values when the density share of three-wheelers becomes less than $3 \%$. This shows that vehicles, which have much lower average speeds than the other vehicles in the traffic stream, affect the capacity of the road even at low densities. A slow moving tractor has a high PCU value when overtaking opportunities become less on undivided roads. The tractor group on the two-lanes with $2.5 \mathrm{~m}(8 \mathrm{ft})$ paved shoulders has the highest PCU value. One expected this as tractor density in table 8 shows that a very low density exists for the tractor type on this highway, and the tractor type has a wide spread of the 85th percentile width distribution. Table 13 shows that a single Indian passenger-car in non-homogeneous conditions is equivalent to less than one passenger car in homogeneous conditions on twolanes highways without shoulders. On single lane highways, intermediate lane, two lanes with $2.5 \mathrm{~m}$ shoulder, and four-lanes divided, it is more than one homogeneous passenger car. All 34 sites had almost no breakdown in traffic during the peak periods of videotaping, 1.5 to 3 hours in duration. Free flow conditions generally prevailed at the rural and suburban sites on the single lane and intermediate lane highway sites.

By using $f_{\mathrm{PCU}}$, one can convert non-homogeneous traffic based PCUs into their homogeneous counterparts. For homogeneous traffic, one can calculate PCUs assuming a standard

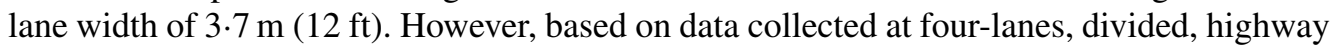
sites throughout India, the 85th percentile width that the passenger car type uses on fourlanes divided highway was $5.5 \mathrm{~m}(18 \mathrm{ft})$. Stated another way, $85 \%$ of passenger cars used a pavement width of $5.5 \mathrm{~m}(18 \mathrm{ft})$ out of a total pavement width of $12 \mathrm{~m}(39 \mathrm{ft})$. The resulting PCU and $f_{\mathrm{PCU}}$ are applicable to those Indian highway types in rural and suburban areas. These values do not apply to urban facilities. The $f_{\mathrm{PCU}}$ values also show how traffic dynamics change for each Indian highway type. The closer the values are to one, the more the Indian non-homogeneous traffic behaves like homogeneous traffic.

Multiplying $f_{\mathrm{PCU}}$ by the Indian PCUs converts most non-homogeneous traffic to its homogeneous equivalent. For example, 120 Indian passenger cars, 50 Indian heavy vehicles and 25 Indian motorized two-wheelers in one direction on a four-lanes divided highway are equivalent to 412 passenger cars in homogeneous traffic, i.e., $\left(120+50^{*} 2 \cdot 1+25^{*} 2 \cdot 0\right)^{*} 1 \cdot 5$, or 275 Indian passenger cars in homogeneous traffic. The same traffic conditions above but on a two-lanes road without shoulders is 178 passenger cars in homogenous traffic, i.e., 
$\left(120+50^{*} 1 \cdot 1+25^{*} \cdot 9\right)^{*} \cdot 9$, or 198 Indian passenger cars. For the same widths of roadway and equal average speeds, non-homogeneous traffic using rural and suburban facilities has less traffic entity throughput than homogeneous facilities, i.e., lower capacity. However, if average speeds approach mean, non-motorized speeds such as in dense urban street traffic, non-homogeneous traffic has more throughput (Fazio et al 1999). Traffic engineers can incorporate these equivalencies into transportation software applications and models that modellers calibrate using homogeneous traffic concepts.

\section{Conclusions}

The modified density method recognizes the loose lane discipline characteristic of nonhomogeneous traffic. Rural non-homogeneous traffic that includes large percentages of trucks, farm vehicles, tractors, three-wheelers, two-wheelers, bicycles, and animal drawn carts exhibits a wide variation in static and dynamic characteristics of traffic entities. Vehicles such as buses, trucks and cars with a possible maximum speed of over $100 \mathrm{~km} / \mathrm{h}(62 \mathrm{mi} / \mathrm{h})$ share the carriage way with tractors and bicycles with a possible maximum speed of $30 \mathrm{~km} / \mathrm{h}$ $(19 \mathrm{mi} / \mathrm{h})$ and $15 \mathrm{~km} / \mathrm{h}(9 \mathrm{mi} / \mathrm{h})$, respectively. Often vehicles in this traffic mix do not use the delineated lanes. Traffic entities of similar speeds and size pre-segregate into the most efficient and safest distribution possible across the pavement width. Traffic entities per unit area account for varying 85th percentile highway widths used by different traffic entity types.

Large PCUs of slow moving vehicles even at low density explain that these vehicles consume a disproportionately high capacity on highways where traffic streams include a variety of modes. This is true in a large number of low-income Asian and African countries. Homogenized behaviour of vehicles and their drivers could contribute to increased capacities. This makes a strong case for including service lanes for slow moving vehicles for improving the capacity of highways. If service lane designs became successful in attracting all slow moving traffic, e.g., bicycles, animal carts, and tractors away from the main carriageway, a large release of capacity would occur on the main highway for motorized vehicles. These designs would reduce the speed variation of traffic on the main carriageway and lead to fewer conflicts, more safety improvements, and improved operations of the traffic stream. Provision of a service lane can serve slow and local traffic, as a capacity enhancement strategy would have higher benefit cost ratio as compared to adding an extra lane on the main carriageway without a service lane. For example, four-lanes divided highways with service lanes will be a better option than six-lanes divided highways without service lanes for rural and suburban sites with non-homogeneous traffic.

\section{References}

Bang K L, Ronggui Z, Huichen X 1998 Traffic performance and passenger car equivalents for road links and township roads in PRC, Proc. Third International Symposium on Highway Capacity, (Copenhagen: Danisu Road Directorate) 257-273

Bang K L, Carlsson A, Palgunadi 1995 Development of speed-flow relationships for indonesian rural roads using empirical data and simulation. Transportation Research Record 1484 (Washington, DC: National Academy Press)

CRRI 1982 Road user cost study in India, Final Report (New Delhi: Central Read Research Institute)

Cunagin W D, Messer C J 1982 Passenger car equivalents for rural highways, Report FHWA/RD82/132 (Washington, DC: FHWA, US Department of Transportation) 
Fazio J, Hoque M M, Tiwari G 1999 Fatalities of heterogeneous street traffic. Transportation Research Record 1695 (Washington, DC: National Academy Press) 55-60

Fazio J, Tiwari G 1995 Non-motorized-motorized traffic accidents and conflicts on Delhi streets. Transportation Research Record 1487 (Washington, DC: National Academy Press) 68-74

Gerlough D L, Huber M J 1975 Traffic flow theory: A monograph (Washington, DC: Transportation Research Board)

Highway Capacity Manual 2000 Transportation Research Board (Washington, DC: National Research Council)

Kadiyali L R, Vishwanathan E 1992 Study for updating road user cost data. Journal of Indian Roads Congress 54(3): 645-731

McShane W R, Roess R P 1990 Traffic engineering, Prentice-Hall, Englewood Cliffs, NJ

Road Accidents in Delhi 2004 Accident Research Cell, Delhi Traffic Police (New Delhi, India)

Wardrop J 1952 Some theoretical aspects of road traffic research proceedings of the Institution of Civil Engineers, 1: 325-378

Webster N and Elefteriadou L 1999 A simulation study of truck passenger car equivalents (PCE) on basic freeway sections Transportation Research Part B: Methodological 33(5): 315-385 